Article

\title{
Pro-Environmental Energy Behavior in the Military: Assessing Behavior Change Factors at a Selected Military Unit
}

\author{
Rasa Smaliukiene ${ }^{1,2, *}$, Gintaras Labutis ${ }^{1}$ and Ausrius Juozapavicius ${ }^{1}(\mathbb{D}$ \\ 1 General Jonas Zemaitis Military Academy of Lithuania, Silo 5a, 10322 Vilnius, Lithuania; \\ gintaras.labutis@lka.lt (G.L.); ausrius.juozapavicius@lka.lt (A.J.) \\ 2 Department of Creative Communication, Vilnius Gediminas Technical University, Sauletekio 11a, \\ 10223 Vilnius, Lithuania \\ * Correspondence: rasa.smaliukiene@lka.lt
}

Received: 2 December 2019; Accepted: 26 December 2019; Published: 2 January 2020

\begin{abstract}
The purpose of this study is to explore how pro-environmental energy behavior is manifested at a military unit and what behavioral change factors can enhance such behavior. The military unit represents an organization dominated by an exceptionally strong sense of community and belonging where individual pro-environmental energy behavior goes in line with a collective one. The application of Capability-Opportunity-Motivation-Behavior (COM-B) approach led to a better understanding of energy-saving behavior in the military as an organization where personnel are trained to increase their awareness of their peers' behavior. Methods: The results were obtained using data collected from two independent samples of both professional soldiers and conscripts at a military unit of Lithuanian defense forces located in a fixed installation in the time frame of 2018-2019. The total sample of respondents (professional soldiers and conscripts) was $\mathrm{N}=454$. A series of statistical tests were performed at the 0.05 level of confidence. Results: An extended COM-B model for the analysis of pro-environmental energy behavior in the military was proposed and applied. The results show that the three behavioral change factors - capability, opportunity, and motivation-are first of all positively linked with the collective energy behavior at the military unit and only then with the individual soldier's pro-environmental energy behavior. This is a new insight into the COM-B model as collective and individual behavior are identified as separate indicators and then combined into a single measurable construct. In addition, the results indicate that in the military unit, communality plays an important role in sustaining pro-environmental energy behavior, even if an individual behavior indicates low-involvement.
\end{abstract}

Keywords: energy security; pro-environmental behavior; energy usage; military energy behavior; behavioral change; COM-B; collective behavior; conscripts; professional soldiers

\section{Introduction}

Attention towards energy and energy security over the last decade increased as the efficient military energy usage is considered to be one of the key enablers of military operational capabilities. This trend is reflected in European Union (EU) and NATO strategic priorities and initiatives that underline the importance of ensuring energy security for military operations as well as reducing the environmental impact of military operations [1-3]. In addition, a portion of research, technology, and innovation (RTI) projects in military and defense are focused on energy and particularly on renewable energy solutions. In general, three key factors that affect energy usage can be listed: energy generation technologies, energy management, and energy data collection and analysis systems together 
with energy behavior at military units $[4,5]$. Resonating with an overall trend in energy transition towards pro-environment energy usage [6-8], military RTI initiatives stress on technological solutions. Meanwhile, the energy behavior remains an inadequately explored factor in reducing the energy usage and thus increasing military energy security [9] and energy efficiency [10]. Even though energy behavior in the military is gaining more attention, overall attempts in changing energy behavior of military personnel remains a managerial challenge.

The Capability-Opportunity-Motivation-Behavior (COM-B) model proposed by Michie et al. [11] and tested in numerous research projects is applied in this paper to investigate the energy-saving behavior in the military. The application of COM-B model to energy behavior leads to a better understanding of pro-environmental behavior in the military and facilitates a detailed analysis of the factors affecting this behavior. The model works in a context where three factors of the behavior (capability, opportunity, and motivation) are surrounded by managerial interventions, organizational policies, and limitations.

In the military context energy behavior is rooted into the trilemma of: (i) how to assure energy security for the military operations, (ii) how to use energy efficiently, and (iii) how to reduce the environmental impact of the operations [1]. In this context, energy behavior plays a critical role after the energy policies and standard operating procedures are introduced and related technologies are deployed. All three considerations are gradually translated into the requirements for the United Nations (UN) peacekeeping operations as well as EU and NATO military environment promoting not only technological development but also energy behavioral changes. Specifically, the UN peacekeeping forces had implemented environmental policies in all peacekeeping missions since 2009 [12]. This includes the requirements for environmental management systems that include energy, water, and waste management. As a new step in promoting pro-environmental energy usage in the military, the UN introduced its Environment Strategy of the UN Department of Field Support (DFS) which came into effect in January 2017. Its energy related objective "to reduce overall demand for energy through efficiencies" is planned to be realized by 2023 [2] (p. 2). This includes not only the requirements for energy efficient infrastructure but also the behavioral incentives where "awareness-raising and behavioral change" [2] (p. 2) play an important role. In general, the UN initiatives complement NATO's approach on energy security, energy resilience, and the protection of critical energy infrastructure. The improvement of energy efficiency becomes one of the key priorities $[10,13]$, therefore NATO's approach is also focused on the military by "reducing the energy consumption of military vehicles and camps, as well as minimizing the environmental footprint of military activities" [14]. At the Brussels Summit in 2018, those priorities were emphasized to the Member States underlining the importance of "more education and training opportunities" [3]. This highly resonates with energy priorities in security and other sectors [15]. Energy and energy security as the strategic priority was elaborated through the activities of NATO Energy Security Center of Excellence that was established in Lithuania in 2012 in order to assist Strategic Commands, other NATO bodies, nations, partners, and other civil and military entities by supporting NATO's capability development process, mission effectiveness, and interoperability by providing comprehensive and timely subject matter expertise on all aspects of energy security.

Given the situation where the energy policies and standard operating procedures are already introduced, and energy related technologies are deployed the COM-B model explaining the behavior change factors becomes an effective tool for the further research of military energy behavior. According to the model's designers Michie et al. [11], three factors heavily influence the behavior: capability (C), opportunity $(\mathrm{O})$, and motivation (M) (Figure 1). The model explores individual's behavior in the organizational context and provides the basis for managerial interventions [16], as well as includes main steps for behavioral change [17]. According to this model, all three conditions must be met in order to make an influence on individual's energy behavior: the individual's physical and social capability, individual's social and physical ability to explore new opportunities, and self-motivation as the crucial part of the behavior change [18]. This model was theoretically grounded and applied in 
a wide variety of contexts: nutrition [19], smoking [20], physical activity [21], as well as for energy use by households [22] and other end-users [23]. The COM-B model was applied to improve energy behavior in the military too [14,24]. However, those behavioral interventions in military and defense were purely practical and lacked intrinsic validity. This suggests that the COM-B model should first of all be tested as a solution/construct in the military context.

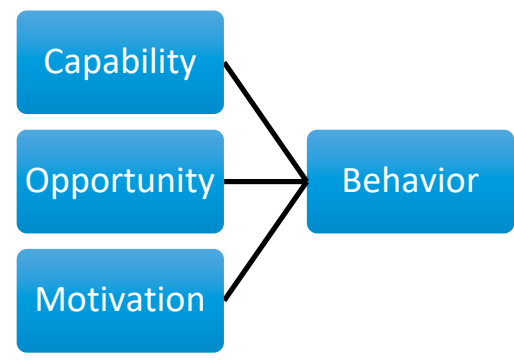

Figure 1. The original construct of COM-B model for behavioral change $[11,16,21]$.

Assuming that a military context differs from a civilian context, the COM-B model needs to be validated and factors influencing the pro-environmental energy behavior in the military need to be identified. Studies showed that military members are indoctrinated already at the beginning of their military career [25]. Consequently, military culture penetrates attitudes and behavior, whereas individuals report strong identification with the military [26-28]. The military's impact on an individual increases along the duration of the military service [29]. Based on this evidence it could be assumed that the awareness of energy criticality in the military is increasing over the years of service, as shown by research in military energy efficiency [10]. Capability, opportunity and motivation affecting pro-environmental energy behavior are positively strengthened with the understanding that energy in military is considered to be a critical combat's "tooth" [1]. These considerations are taken into account when planning and conducting military operations for professional soldiers as well as for military conscripts. It is also assumed that the conscripts' perception of the importance of energy in the military differs from the professional soldiers. The conscripts are serving for a short term and they can be not yet fully indoctrinated [30]. Their capabilities, opportunities, and motivation to behave in a pro-environmental way could be linked to their civil life experiences of a green lifestyle [31] and not to the military service.

Efficient usage of military equipment and infrastructure is perceived as a potential for the freedom of action and an opportunity for enhanced capabilities of the military operations [1]. Consequently, important parts of the military's RTI are directed at addressing those issues. For example, new technologies that are used in expeditionary environment as well as in fixed military installations are focused on improving energy supply and reducing the usage [32,33], but the awareness of energy behavior remains limited. Despite the emphasis on technical solutions related to energy, the call for behavioral change at a unit level remains a priority $[10,34]$. Considering that at military bases soldiers are semi-isolated from their existing ties as well as their life outside the military, their bond with a military unit rises [35], and therefore, pro-environmental energy behavior must be analyzed not only from an individual's behavioral perspective, but also from the individual's social identification with the military unit. During the demanding military training, professional soldiers as well as conscripts are trained in order to increase their awareness of their own behavior in the context of the unit and their peers [35]. Therefore, COM-B model must focus not only on the individual's behavior, but also include the collective military behavior of the military unit.

The unique feature of our research is that we disaggregate two groups of energy behavior: individual energy behavior ("my" behavior) and unit energy behavior ("our" behavior). While the former follows the COM-B traditional paradigm used and validated in a series of studies (e.g., $[11,16,21,36])$, the latter relies exclusively on military research that puts a stress on soldier's bond with a military unit $[28,37]$. 
The purpose of this study is to explore how a politically and institutionally favorable environment that forces military transition towards the pro-environmental energy behavior is reflected at a military unit level. The rest of the paper proceeds as follows. First, we outline our research instrument and measurement model by extending the construct of COM-B model for behavioral change in the military. Next, we perform data analysis using a series of statistical tests. By applying the COM-B model we investigate energy behavioral factors and postulate that the three behavioral change factors-capability, opportunity, and motivation-are positively linked not only with individual soldier's behavior, but also with a collective energy behavior of the unit. Finally, discussion and conclusions are presented in the last section.

\section{Materials and Methods}

To measure the relationships between energy behavior in the military and affecting factors we collected data by making an annual survey for two consecutive years. The research was performed using traditional paper questionnaires at a selected Lithuanian military unit (fixed installation). The first survey was executed in October 2018 followed by the second survey in October 2019. During the first stage of data collection, 235 soldiers, non-commissioned officers, and officers were surveyed, while during the second stage the number of respondents was 219 soldiers, NCOs, and officers. Most respondents were conscripts (70 percent), followed by professional soldiers, NCOs, and officers (30 percent). Hence, the total sample was $\mathrm{N}=454$. Detailed demographic information of the respondents is presented in Table 1. In some categories, the sum of all answers is less than $100 \%$ due to some missing responses. They were eliminated from further analysis.

Table 1. Demographic information of the respondents.

\begin{tabular}{cccccc}
\hline \multirow{2}{*}{ Category } & Description & \multicolumn{2}{c}{ Year: 2018 } & \multicolumn{2}{c}{ Year: 2019 } \\
\cline { 2 - 6 } & $\begin{array}{c}\text { Number of } \\
\text { Respondents }\end{array}$ & Percentage & $\begin{array}{c}\text { Number of } \\
\text { Respondents }\end{array}$ & Percentage \\
\hline \multirow{2}{*}{ Gender } & Female & 31 & $13 \%$ & 23 & $10 \%$ \\
\cline { 2 - 6 } & Male & 204 & $87 \%$ & 196 & $90 \%$ \\
\hline \multirow{2}{*}{ Age } & 20 or below & 77 & $33 \%$ & 69 & $32 \%$ \\
\cline { 2 - 6 } & $21-30$ & 115 & $49 \%$ & 132 & $60 \%$ \\
\hline \multirow{2}{*}{ Service type } & 30 or more & 43 & $18 \%$ & 18 & $8 \%$ \\
\hline & Professional soldier & 85 & $36 \%$ & 44 & $20 \%$ \\
\hline $\begin{array}{c}\text { Participated in previous } \\
\text { energy-saving initiatives }\end{array}$ & Conscript & 147 & $64 \%$ & 172 & $79 \%$ \\
\cline { 2 - 6 } & Yes & 28 & $12 \%$ & 29 & $13 \%$ \\
\hline
\end{tabular}

The questionnaire consisted of Likert one-to-five scale questions where value 1 corresponded to "strongly agree" and value 5 to "strongly disagree". In total there were 18 randomly listed statements related to COM-B measuring three latent variables: Motivation to save energy, Capabilities of the respondents, and available opportunities to exhibit the energy-saving behavior. Five statements were related to the capability category, seven statements to the opportunity category, and four to motivation. Two questions were attributed to the behavior category; they are analyzed later in the text. The ordinal scale of Likert questions limited statistical comparisons, and therefore several questions were included to measure the same variable, e.g., if three questions are used then the sum of the answers to these questions goes from 3 to 15, therefore it can be treated as an interval variable. We used Cronbach's alpha (CA) coefficient to measure the internal consistency of the composing questions. During the process, one motivation-related question and two capability-related questions were eliminated from 
further analysis due to their detrimental effect on the CA coefficient of the corresponding variables. In other words, they were independently measuring something else than intended.

The three latent variables, their questions, and reliability (the CA coefficients) are presented in Table 2. Observed variables were also validated individually: none of them have more than $5 \%$ of the missing values. Average values of all questionnaire answers are presented in Figure 2.

Table 2. Variables and their corresponding questions of the COM-B questionnaire.

\begin{tabular}{|c|c|c|c|c|}
\hline Latent Variable & Question & Coding & $\begin{array}{c}\text { Factor } \\
\text { Loading }\end{array}$ & $\begin{array}{l}\text { Cronbach's } \\
\text { Alpha }\end{array}$ \\
\hline \multirow{3}{*}{$\begin{array}{l}\text { Motivation (M) scale: } \\
3 \text { (best)-15 (worst) }\end{array}$} & I want to save energy & M1 & 0.75 & \multirow{3}{*}{0.718} \\
\hline & I think it is important to save & M2 & 0.70 & \\
\hline & I'd like to do something about saving & M3 & 0.77 & \\
\hline \multirow{7}{*}{$\begin{array}{l}\text { Opportunity }(\mathrm{O}) \text { scale: } \\
\qquad 7-32\end{array}$} & I know about energy-saving activities ${ }^{1}$ & O1 & 0.74 & \multirow{7}{*}{0.621} \\
\hline & Superiors care about saving energy & $\mathrm{O} 4$ & 0.30 & \\
\hline & It is possible for me to save energy & $\mathrm{O} 2$ & 0.69 & \\
\hline & Saving does not interfere with my activities & O3 & 0.24 & \\
\hline & Saving energy decreases our operational capabilities ${ }^{2}$ & O5 & 0.84 & \\
\hline & Saving energy decreases our operational security ${ }^{2}$ & O6 & 0.83 & \\
\hline & My colleagues would laugh at me for saving energy ${ }^{2}$ & O7 & 0.68 & \\
\hline \multirow{3}{*}{$\begin{array}{l}\text { Capability }(\mathrm{C}) \text { scale: } \\
\quad 3-15\end{array}$} & $\begin{array}{l}\text { I feel I have a good understanding where the energy } \\
\text { losses are largest }\end{array}$ & $\mathrm{C} 1$ & 0.65 & \multirow{3}{*}{0.508} \\
\hline & I know how to save energy at work & $\mathrm{C} 2$ & 0.13 & \\
\hline & I receive information about saving energy & $\mathrm{C} 3$ & 0.84 & \\
\hline
\end{tabular}

${ }^{1}$ The question had only two values-Yes and No. ${ }^{2}$ The answers had to be inverted before performing the analysis.

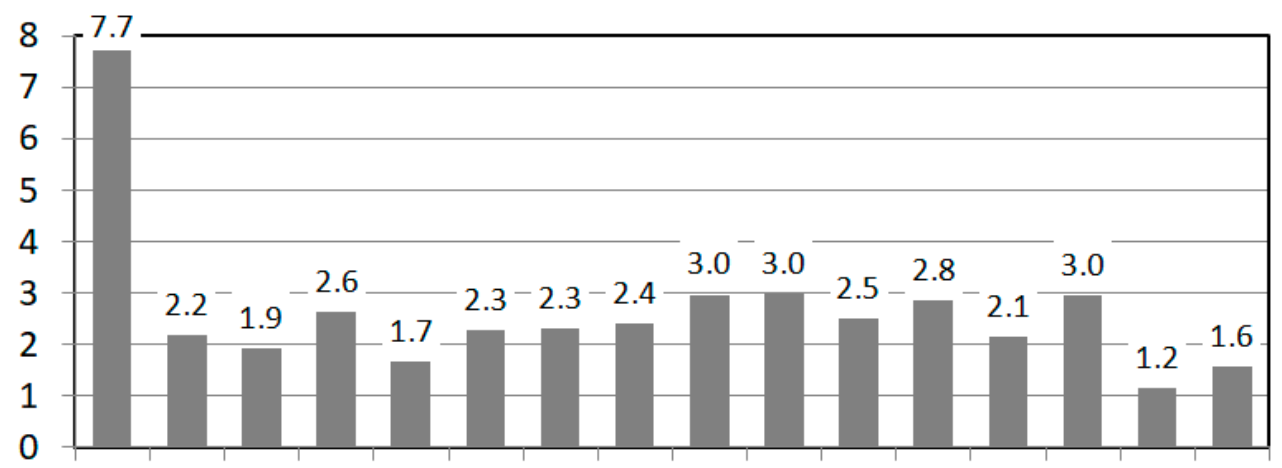

\section{S $\begin{array}{lllllllllllllll}\text { M1 } & \text { M2 } & \text { M3 } & 01 & 02 & 03 & 04 & 05 & 06 & 07 & \text { C1 } & \text { C2 } & \text { C3 } & \text { B1 } & \text { B2 }\end{array}$}

Figure 2. Average values of all answers. "S" denotes overall satisfaction (max 10$)$, "B1" - "my" behavior, "B2"- “our" behavior, other variables are defined in Table 2, and they range from 1 (best) to 5 (worst).

Additionally, we performed the principal component analysis on all answers of the questionnaire using SPSS software in order to assess its internal consistency. Sum of eigenvalues of the main five components covered almost $60 \%$ of the variance. The first component corresponded exactly with the motivation questions, explaining their high CA coefficient and the reliability of measurement. The questions have high loading factors above 0.7 (see Table 2) and their contribution to other latent variables is negligible. The second component grouped questions $\mathrm{C} 1$ and $\mathrm{C} 3$, with the $\mathrm{C} 2$ question also having a large load (0.71) in the third component and therefore significantly decreasing the reliability of capability measurements-it is the lowest among the latent variables. The remaining seven questions were grouped into three components separated in Table 2 by horizontal lines, where O5, O6 and O7 constituted the strongest component of the three, $\mathrm{O} 1$ went together with $\mathrm{O} 4$, and the last component consisted of $\mathrm{O} 2$ and $\mathrm{O} 3$. Together the seven questions were assigned to the opportunity variable as 
initially intended. Overall, the analysis validated the independence of the three latent variables and the reliability of their measurement.

According to the COM-B model [38] the behavior is determined by the three constituting factors: the previously defined latent variables Capability $(C)$, Opportunity $(O)$, and Motivation $(M)$. For the purposes of further analysis of the data, the three variables were combined into a single COM variable:

$$
C O M=1-[(C-3) / 12+(O-7) / 25+(M-3) / 12] / 3
$$

where the scale of each variable is shifted to zero and normalized to 1 so that their contribution has the same weight, and then the normalized sum value is inverted to produce the combined COM variable with values from 0 (worst) to 1 (best).

Variable B (behavior) was tested using two separate questions that represent connotations related to "My" versus "Our" energy behavior. It differs from the original COM-B construct presented in Figure 1 where only one behavioral indicator is foreseen. We took into consideration the uniqueness of the military culture where collective behavior and soldiers' psychological bond with his/her unit is manifested and adopted the COM-B model to the military context. "My" behavior (B1) was measured using a statement "I turn off the electricity when I stop using it". For "Our" energy behavior (B2) we used a statement that represents a commitment to unit's performance: "We manage energy well in the unit". All together these two statements created a We-I behavioral construct for measuring energy behavior in the military (Figure 3). These statements were measured using the Likert scale. Taking into consideration that COM-B model works in a context, we additionally tested an overall workplace satisfaction (see variable "S" in Figure 2) of the soldiers using one 10-point Likert scale question.

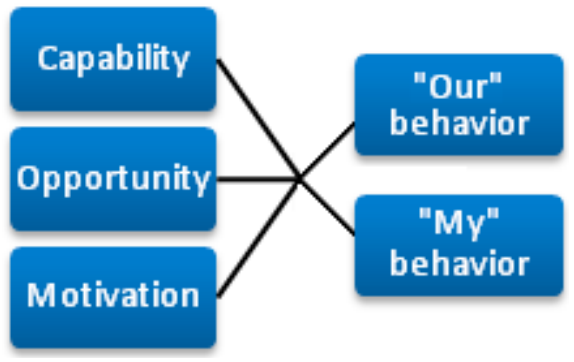

Figure 3. An extended construct of COM-B model for behavioral change in the military.

\section{Results}

Using the COM variable, we performed a series of tests for different groups of respondents at the 0.05 level of confidence. We found a statistically significant COM increase of $12 \%$ among those who had participated in some energy-saving initiatives $(C O M=0.64)$ versus the other group $(C O M=0.57)$, see Table 3. It is important to note that the number of those who had participated in energy-saving initiatives is relatively low and does not differ between the years.

Table 3. Comparison of Capability-Opportunity-Motivation (COM) values for different groups of respondents.

\begin{tabular}{ccccc}
\hline \multirow{2}{*}{ Category } & \multirow{2}{*}{ Description } & \multicolumn{3}{c}{ COM } \\
\cline { 3 - 5 } & & $\mathbf{2 0 1 8}$ & $\mathbf{2 0 1 9}$ & Total \\
\hline \multirow{2}{*}{ I participated in previous energy-saving activities } & Yes & 0.63 & 0.65 & 0.64 \\
& No & 0.57 & 0.56 & 0.57 \\
\hline \multirow{2}{*}{ I turn off electricity when I stop using it } & Yes & 0.59 & 0.58 & 0.59 \\
& No & 0.52 & 0.54 & 0.53 \\
\hline \multirow{2}{*}{ Service type } & Professionals & 0.60 & 0.60 & 0.60 \\
& Conscripts & 0.57 & 0.57 & 0.57 \\
\hline
\end{tabular}


Similarly, respondents who reported energy-saving behavior had a statistically significant $9 \%$ higher $C O M$ (average $C O M=0.59$ ) than their colleagues who do not exhibit energy-saving behavior (average COM $=0.53$ ). The results stand well with the COM-B theory where higher capabilities, opportunities and motivation influence a better behavior.

To determine the context of COM-B we measured how an overall satisfaction with the military service is influencing COM. The satisfaction (see Figure 4) measured from 1 (lowest) to 10 (highest) has a 0.49 correlation coefficient with the COM variable (at the 0.01 significance level). This is not surprising as we expected the satisfaction to be related with the motivation variable.

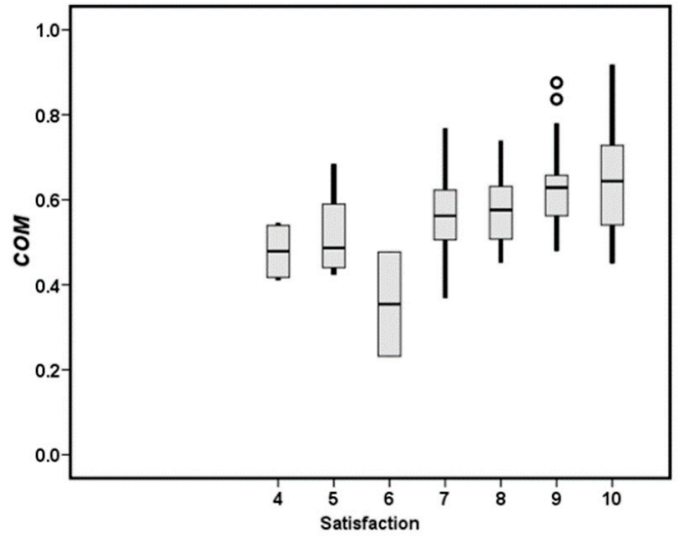

(a)

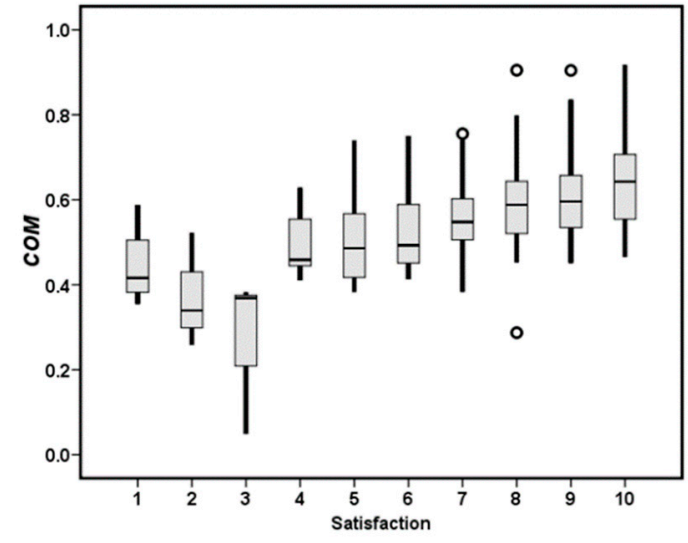

(b)

Figure 4. Interdependency between overall satisfaction with the service and the COM variable (Capability-Opportunity-Motivation) of: (a) professional soldiers, (b) conscripts.

Considering the uniqueness of our sample that consists of professional soldiers and conscripts we checked whether there are any differences between these two groups of respondents one year apart. There was no statistically significant difference in average COM value indicating independent groups of responders as a large part of the professional soldiers was rotated and all the conscripts were replaced over that year. Meanwhile, the $T$-test of independent samples suggested a statistically significant although quite small difference in energy-saving behavior between the professional soldiers and conscripts: the average $C O M$ value of professional soldiers $(0.60)$ exceeded the corresponding value of conscripts (0.57) by $5 \%$.

In testing our main statement that COM is positively linked not only with individual soldier's behavior, but also with collective energy behavior of the unit, we measured the impact of the behavioral factors on an individual's behavior ("my" behavior) in relation to collective energy behavior of the unit ("our" behavior). For this reason, we split the respondents into 6 different subgroups based on their responses about their own behavior and the collective energy behavior of the unit. The groups and their corresponding COM values are presented in Table 4. The first column shows the energy-saving behavior of the unit as reported by a respondent: a plus sign is given when the respondent positively evaluated the collective energy behavior, a minus for the negatively reported behavior, and a zero when the respondent reported a neutral behavior. The second column has two values depending on whether the respondent herself/himself exhibits energy-saving behavior (either a plus or a minus). One-way analysis of variance (ANOVA) showed a significant difference in mean COM values between all groups. The results show a much stronger effect of COM value on "our" behavior than on "my" behavior.

Individually, each of the behavior variables positively correlates with the COM variable-the correlation coefficient is 0.45 for "our" behavior and 0.16 for "my" behavior. This can be observed in Figure 5, where the behavior becomes more positive as the COM variable grows. 
Table 4. COM values with "our" and "my" energy-saving behavior.

\begin{tabular}{ccc}
\hline “Our" Behavior & “My” Behavior & Mean COM Value \\
\hline+ & + & $0.6319^{1}$ \\
+ & - & $0.5691^{1}$ \\
0 & + & $0.5396^{1}$ \\
0 & - & $0.5305^{1}$ \\
- & + & $0.5199^{1}$ \\
- & - & $0.4319^{1}$ \\
\hline
\end{tabular}

${ }^{1}$ The mean difference is significant at the 0.05 level.

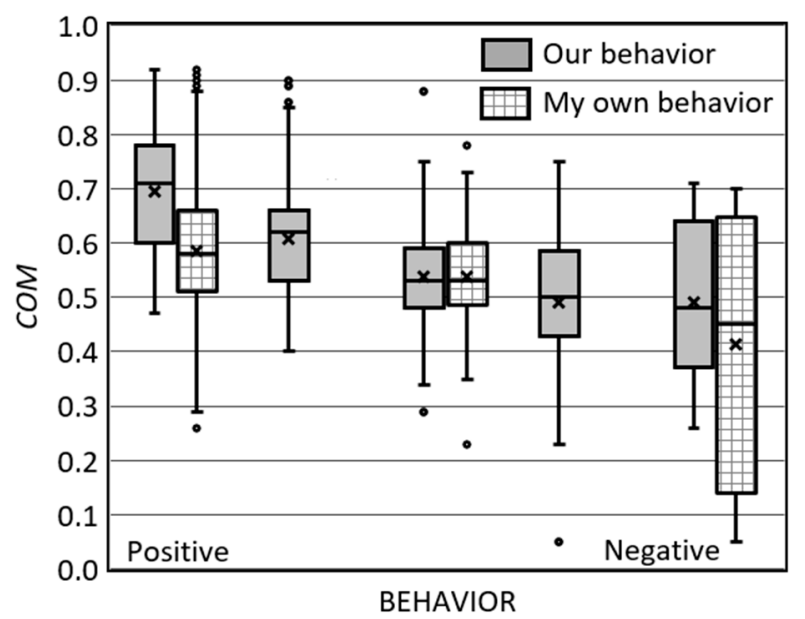

Figure 5. Capability-Opportunity-Motivation variable (COM) versus the self-reported energy-saving behavior of an individual (white hatched boxes-"my" behavior) and a group (grey boxes - "our" behavior).

\section{Discussion}

This study fills the gap in the research on military energy behavior and suggests that pro-environmental energy behavior in the military is linked not only with an individual soldier's attitudes and intentions, but also with its military unit. Institutionally favorable environment that forces military transition towards the pro-environmental energy behavior is reflected as a collective action. So far, many studies focused on technical solutions for reducing energy usage $[33,39,40]$ and enabling decision makers $[5,14,41]$ and individual soldiers $[10,24]$ to save energy. It appears that this research for the first-time underlines collectivity and connects individual and collective pro-environmental energy behavior into one measurable construct.

Pro-environmental energy behavior in the military should be considered in a special way as military culture penetrates attitudes and behavior [26,28]. Respectively, our conceptual construct that includes a collective energy behavior goes in line with other studies designed for communality in the military. Transformation from " $\mathrm{I}$ " to " $\mathrm{We}$ " is unique to the military as it serves as a protective psychological construct in difficult exercises and war situations [35]. According to our findings, in the case of pro-environmental energy behavior, this transformation makes a positive impact on both the collective and the individual behavior. These findings go in line with the findings where macro influences on energy behavior are discussed. According to the comprehensive review of studies about energy behavior in organizations, energy behavior is driven by broad social and institutional considerations $[7,42]$. In response to this statement, our research findings indicate that in the military unit communality acts as the factor of sustaining pro-environmental behavior, i.e., when the change factors decrease, the unit still exhibits a positive behavior even if individual's pro-environmental energy behavior might falter. 
The segregation of collective and individual behavior is a fundamentally new approach in COM-B model testing. These results can be explained by the fact that the COM-B model was not tested before in organizations or communities where communality (strong sense of belonging) is more important than individual contribution. At the same time, the results are consistent with research results from various fields in the military and shows that a collective identity becomes more important than an individual soldier's identity $[1,27,43]$. For example, the collective identity was found dominating in the research on military innovations [27], where a unique military culture was found manifesting. Similarly, studies on leadership in the military [44] are predominately concerned about the function of military leaders to create subordinates' emotional attraction to the organization which in turn increases commitment and resilience of soldiers.

Despite the segregation of the behavioral element, energy behavior in the military unit follows the classical COM-B model. Just like other researchers, we adopted the construct to the context of the organization. Thus, the results of this study resonate with the evidence of other studies using the COM-B model: the model is constructed with three statistically reliable indicators: capabilities, opportunities and motivation $[11,21,45]$. In addition, the overall variance of the variables compares to the other energy behavioral models (e.g., [15,46-48]).

Furthermore, our research goes in line with the findings of research that energy-saving behavior is a learned behavior [49]. In our study, those who participated in prior energy-saving initiatives reported a more positive energy-saving behavior. Energy behavior is a learned entity, thus prior experience increases the level of capability and splits energy users into groups according to this component. These findings are in line with the COM-B approach where the capability is one of three behavioral change factors [11,45].

Although the results of this study test behavioral change factors of energy behavior at a military unit, certain limitations need to be considered. Firstly, the data was collected at a unit located in a fixed installation only. To overcome this limitation, data was collected twice for two consecutive years to level out the operational tempo at the unit. The relative consistency of behavioral data suggests that these differences are minimal.

Secondly, the behavioral indicators of individual and collective behavior are measured using only a few questions. This is since the questionnaire response time was shortened to $10 \mathrm{~min}$ so as not to distract soldiers from their tasks. Therefore, the behavioral indicator was measured only with two measures: one for the individual and one for the collective behavior. Separation of individual and collective behavior was not foreseen from the start of this study-it became evident only during the data analysis. Despite this limitation, the relationship between COM and behavioral factors is statistically strong. However, in future research, we suggest using several measures for individual and for collective behavior.

Based on this discussion, the research has a few practical implications:

For practitioners in the military, these results are interesting for gaining statistically tested model for pro-environmental energy behavior change. Our findings point out that pro-environmental energy behavior in the military unit follows the classic COM-B model with one exception: behavior (element B) is segregated into two components: collective and individual behavior. This revised model can be applied in practice and used to measure behavioral change when behavioral interventions are applied in the unit.

For practitioners in other than military organizations, this analysis demonstrates the duality of collective and individual factors in energy behavior. Our findings point to an importance of communality in the organization. Communality makes an impact on capability, opportunity, and motivation in pro-environmental energy behavior in an organization. Specifically, the findings indicate that in the organization with a strong sense of belonging, collective pro-environmental behavior remains active even if an individual behavior indicates low-involvement. 


\section{Conclusions}

This study addresses personal and collective factors emerging in energy behavior in a military unit. These are the main conclusions from the study:

First, collective and individual behavior has to be segregated while testing energy behavior in a military unit. The research findings justify this conceptual segregation and show that the dependence between the behavior change factors and the collective energy-saving behavior is pronounced more than the dependence between the factors of the individual's behavior. The segregation of collective and individual behavior is a fundamentally new approach when testing the Capability-Opportunity-Motivation-Behavior (COM-B) model.

Second, an extended COM-B model can be used while measuring pro-environmental energy behavior in the military. The model validation process led to a construct with three statistically reliable indicators representing the three independent $C O M$ variables. In this construct, the three indicators were formed of a different number of measures, respectively: Capability was defined by three levels of knowledge (I receive information, I know, I understand). Opportunity was defined by seven measures and composed the largest indicator in the construct. Motivation, composed of three measures, was the strongest component of the model.

Third, positive energy behavior is linked with an overall satisfaction with the military service. This finding indicates that the three COM-B model variables-Capability, Opportunity, and Motivation-need to be understood more broadly than only in conjunction with pro-environmental energy behavior. Motivation is the dominant variable of the COM-B model in this study and it is, therefore, linked with the satisfaction too. Military service satisfaction through motivation is said to influence energy behavior in the military unit.

Fourth, there is only a small difference in energy behavior between the professional soldiers and conscripts. This finding demonstrates that while collective behavior prevails over the individual one in the military unit, the time and nature of the military service does not make a significant impact on energy behavior. This confirms the theoretical statements that energy behavior is a learned entity and therefore, further research on energy behavior in military organizations should incorporate this insight.

Author Contributions: Conceptualization-R.S., A.J., G.L.; Data curation, A.J., G.L.; Formal analysis, R.S., A.J.; Investigation, R.S.; Methodology, G.L.; Writing-Original draft, R.S., A.J.; Writing—Review\& editing, A.J., G.L. All authors have read and agreed to the published version of the manuscript.

Funding: This research received no external funding.

Conflicts of Interest: The authors declare no conflict of interest.

\section{References}

1. Samaras, C.; Nuttall, W.J.; Bazilian, M. Energy and the military: Convergence of security, economic, and environmental decision-making. Energy Strategy Rev. 2019, 26, 100409. [CrossRef]

2. DFS. Environment Strategy. Available online: https://peacekeeping.un.org/sites/default/files/171116_dfs_ exec_summary_environment_0.pdf (accessed on 30 October 2019).

3. NATO. NATO's Role in Energy Security. Available online: https://www.nato.int/cps/en/natohq/topics_49208. htm (accessed on 30 October 2019).

4. A Roadmap for Sustainable Energy Management in Defence and Security Sector. Guidance Document 2017. Available online: https://www.eda.europa.eu/docs/default-source/events/eden/phase-i/guidance/ consultation-forum-for-sustainable-energy-in-the-defence-and-security-sector---guidance-document.pdf (accessed on 30 December 2019).

5. Iftimie, I.A. Expeditionary energy economics (e3): The securitization of energy entrepreneurship during megacity counterinsurgencies (a NATO perspective). J. Innov. Entrep. 2018, 7, 4. [CrossRef]

6. Dudin, M.N.; Ivashchenko, N.P.; Gurinovich, A.G.; Tolmachev, O.M.; Sonina, L.A. Environmental entrepreneurship: Characteristics of organization and development. Entrep. Sustain. Issues 2019, 6, 1861-1871. [CrossRef] 
7. Pechancová, V.; Hrbáčková, L.; Dvorský, J.; Chromjaková, F.; Stojanovic, A. Environmental management systems: An effective tool of corporate sustainability. Entrep. Sustain. Issues 2019, 7, 825-841. [CrossRef]

8. Moumen, Z.; El Idrissi, N.E.A.; Tvaronavičienė, M. Water security and sustainable development. Insights Reg. Dev. 2019, 1, 301-317. [CrossRef]

9. Strielkowski, W.; Lisin, E.; Tvaronavičienè, M. Towards Energy Security: Sustainable Development of Electrical Energy Storage. J. Secur. Sustain. Issues 2016, 6, 235-244. [CrossRef]

10. Cerneviciutè, J.; Chichinato, O.; Piccinetti, L.; Raudsepp, M.; Roosalu, T.; Tvaronaviciene, M.; Zimmerman, K. Final Report of the Second Part of the Study Energy Efficiency: Cultural Change; Consortium: Minneapolis, MN, USA, 2016.

11. Michie, S.; Atkins, L.; West, R. The Behaviour Change Wheel: Guide to Designing Interventions, 1st ed.; Silverback Publishing: Sutton, UK, 2014.

12. Environment, Natural Resources and UN Peacekeeping Operations Greening the Blue Helmets United Nations Environment Programme. 2012. Available online: https://wedocs.unep.org/bitstream/handle/20.500.11822/ 8840/UNEP_greening_blue_helmets.pdf?sequence=3\&amp\%3BisAllowed= (accessed on 30 December 2019).

13. El Iysaouy, L.; El Idrissi, N.E.A.; Tvaronavičienè, M.; Lahbabi, M.; Oumnad, A. Towards energy efficiency: Case of Morocco. Insights Reg. Dev. 2019, 1, 259-271. [CrossRef]

14. Melchiorre, T. Recommendations on the Importance of Critical Energy Infrastructure (CEI) Stakeholder Engagement, Coordination and Understanding of Responsibilities in Order to Improve Security; NATO Energy Security Centre of Excellence (NATO ENSEC COE): Vilnius, Lithuania, 2018.

15. Tvaronaciene, M.; Slusarczyk, B. (Eds.) Energy Transformation Towards Sustainability, 1st ed.; Elsevier: Amsterdam, The Netherlands, 2019; ISBN 9-78012-817-6887.

16. Barker, F.; Atkins, L.; de Lusignan, S. Applying the COM-B behaviour model and behaviour change wheel to develop an intervention to improve hearing-aid use in adult auditory rehabilitation. Int. J. Audiol. 2016, 55, S90-S98. [CrossRef]

17. Smaliukienė, R.; Monni, S. A step-by-step approach to social marketing in energy transition. Insights Reg. Dev. 2019, 1, 19-32. [CrossRef]

18. Ojo, S.O.; Bailey, D.P.; Hewson, D.J.; Chater, A.M. Perceived Barriers and Facilitators to Breaking Up Sitting Time among Desk-Based Office Workers: A Qualitative Investigation Using the TDF and COM-B. Int. J. Environ. Res. Public Health 2019, 16, 2903. [CrossRef]

19. Crowley, J.; Ball, L.; Hiddink, G.J. Nutrition care by primary-care physicians: Advancing our understanding using the COM-B framework. Public Health Nutr. 2019, 1-12. [CrossRef] [PubMed]

20. Toblin, R.L.; Anderson, J.A.; Riviere, L.A.; McGurk, D.; Sipos, M.L. The Impact of Unit Membership on Smoking Among Soldiers. Mil. Med. 2016, 181, 16-20. [CrossRef] [PubMed]

21. Howlett, N.; Schulz, J.; Trivedi, D.; Troop, N.; Chater, A. A prospective study exploring the construct and predictive validity of the COM-B model for physical activity. J. Health Psychol. 2019, 24, 1378-1391. [CrossRef] [PubMed]

22. Costello, N.; McKenna, J.; Sutton, L.; Deighton, K.; Jones, B. Using contemporary behavior change science to design and implement an effective nutritional intervention within professional rugby league. Int. J. Sport Nutr. Exerc. Metab. 2018, 28, 553-557. [CrossRef] [PubMed]

23. Wilson, C.; Marselle, M.R. Insights from psychology about the design and implementation of energy interventions using the Behaviour Change Wheel. Energy Res. Soc. Sci. 2016, 19, 177-191. [CrossRef]

24. Maximising Energy Efficiency through Behaviour Change-A UK Case Study Why? Available online: https://www.eda.europa.eu/docs/default-source/events/eden/phase-i/information-sheets/cf-sedssinformation-sheet-maximising-energy-efficiency.pdf (accessed on 29 November 2019).

25. Atuel, H.R.; Castro, C.A. Military Cultural Competence. Clin. Soc. Work J. 2018, 46, 74-82. [CrossRef]

26. Meyer, E.G. The Importance of Understanding Military Culture. Acad. Psychiatry 2015, 39, 416-418. [CrossRef]

27. Adamson, W. Megacities and the US Army. Parameters 2015, 45, 45.

28. Petrauskaitè, A.; Rusko, T. Recent Challenges of Institutional Identity and Contemporary Armed Forces. J. Secur. Sustain. Issues 2018, 7, 561-568. [CrossRef]

29. Tūtlys, V.; Winterton, J.; Liesionienè, O. Institutional aspects of competence-based integration of retired military officers into the civilian labour market. Pers. Rev. 2019, 48, 21-39. [CrossRef]

30. Novikovas, A.; Novikovienè, L.; Shapoval, R.; Solntseva, K. The Peculiarities of Motivation and Organization of Civil Defence Service in Lithuania and Ukraine. J. Secur. Sustain. Issues 2017, 7, 149. [CrossRef] 
31. Kormishkina, L.; Kormishkin, E.; Gorin, V.; Koloskov, D.; Koroleva, L. Environmental investment: The most adequate neo-industrial response to the growth dilemma of the economy. Entrep. Sustain. Issues 2019, 7, 929-948. [CrossRef]

32. Saritas, O.; Burmaoglu, S. Future of sustainable military operations under emerging energy and security considerations. Technol. Forecast. Soc. Chang. 2016, 102, 331-343. [CrossRef]

33. Soni, A. Disruptive Energy Technologies and Military Capabilities. In Disruptive and Game Changing Technologies in Modern Warfare; Springer: Berlin/Heidelberg, Germany, 2020; pp. 115-134.

34. Smaliukiene, R. Sustainability issues in the military: Genesis and prospects. J. Secur. Sustain. Issues 2018, 8, 19-32. [CrossRef]

35. Langan, J.M. PTSD in Military Service Members Recommended Citation. Masthead Logo DePaul J. Health Care Law 2017, 19, 28.

36. Zou, H.; Chen, Y.; Fang, W.; Zhang, Y.; Fan, X. Identification of factors associated with self-care behaviors using the COM-B model in patients with chronic heart failure. Eur. J. Cardiovasc. Nurs. 2017, 16, 530-538. [CrossRef]

37. Williams, J.; Brown, J.M.; Bray, R.M.; Anderson Goodell, E.M.; Olmsted, K.R.; Adler, A.B. Unit cohesion, resilience, and mental health of soldiers in Basic Combat Training. Mil. Psychol. 2016, 28, 241-250. [CrossRef]

38. Cane, J.; Richardson, M.; Johnston, M.; Ladha, R.; Michie, S. From lists of behaviour change techniques (BCT s) to structured hierarchies: Comparison of two methods of developing a hierarchy of BCTs. Br. J. Health Psychol. 2015, 20, 130-150. [CrossRef]

39. Ganesan, A.U.; Nandhagopal, S.; Venkat, A.S.; Padmanaban, S.; Pedersen, J.K.; Chokkalingam, L.N.; Leonowicz, Z. Performance Analysis of Single-Phase Electrical Machine for Military Applications. Energies 2019, 12, 2285. [CrossRef]

40. Jiang, P.; Huang, S.; Zhang, T. Optimal Deception Strategies in Power System Fortification against Deliberate Attacks. Energies 2019, 12, 342. [CrossRef]

41. Kuril, J. Public administration for safe and secure environment: Case of Slovak Republic. Entrep. Sustain. Issues 2018, 5, 493-501. [CrossRef]

42. Andrews, R.N.L.; Johnson, E. Energy use, behavioral change, and business organizations: Reviewing recent findings and proposing a future research agenda. Energy Res. Soc. Sci. 2016, 11, 195-208. [CrossRef]

43. Le Foll, D.; Rascle, O.; Marchal, M.; Cabagno, G. Perceived motivational climate and unit cohesion: The case of French soldiers in training. Mil. Psychol. 2019, 31, 233-240. [CrossRef]

44. García-Guiu, C.; Moya, M.; Molero, F.; Moriano, J.A. El liderazgotransformacional y la potenciagrupalenunidadesmilitarespequeñas: El papelmediador de la identificación y cohesióngrupales. Rev. Psicol. Trab. Organ. 2016, 32, 145-152. [CrossRef]

45. Michie, S.; van Stralen, M.M.; West, R. The behaviour change wheel: A new method for characterising and designing behaviour change interventions. Implement. Sci. 2011, 6, 42. [CrossRef] [PubMed]

46. Pothitou, M.; Hanna, R.F.; Chalvatzis, K.J. Environmental knowledge, pro-environmental behaviour and energy savings in households: An empirical study. Appl. Energy 2016, 184, 1217-1229. [CrossRef]

47. Dumciuviene, D.; Cibinskiene, A.; Andrijauskiene, M. Determinants of Energy Saving: Evidence from a Vocational School in Greece. Energies 2019, 12, 3647. [CrossRef]

48. Paone, A.; Bacher, J.-P. The Impact of Building Occupant Behavior on Energy Efficiency and Methods to Influence It: A Review of the State of the Art. Energies 2018, 11, 953. [CrossRef]

49. Puttick, G.; Kies, K.; Garibay, C.; Bernstein, D. Learning and behavior change in a Girl Scout program focused on energy conservation: Saving energy to save the planet. J. Sustain. Educ. 2015, 8. Available online: http://www.jsedimensions.org/wordpress/wp-content/uploads/2015/01/Puttick-et-al-JSE-Vol-8-Jan2015.pdf (accessed on 30 December 2019).

(C) 2020 by the authors. Licensee MDPI, Basel, Switzerland. This article is an open access article distributed under the terms and conditions of the Creative Commons Attribution (CC BY) license (http://creativecommons.org/licenses/by/4.0/). 